\title{
AVALIAÇÃO DA SATISFAÇÃO NO ENSINO DE PÓS À DISTÂNCIA: A VISÃO DOS TUTORES E ALUNOS DO PNAP/UAB
}

\author{
JÉSSICA SAYURI ISHIDA* \\ Silvio Roberto Stefano** \\ SANDRA MARA DE ANDRADE***
}

Recebido: 12 abr. 2012

Aprovado: 28 ago. 2012

* Universidade Estadual do Centro-Oeste. Guarapuava, PR, Brasil.

Contato com a autora: jessica_ishida@yahoo.com.br

**Departamento de Administração da Universidade Estadual do Centro-Oeste. Guarapuava, PR, Brasil.

Contato com o autor: professor-silvio@hotmail.com

*** Universidade Estadual do Centro-Oeste. Guarapuava, PR, Brasil.

Contato com a autora: smandra_a@hotmail.com

Resumo: Este artigo se originou da pesquisa que teve como objetivo analisar o grau de satisfação dos acadêmicos e tutores em relação aos cursos de especialização do Programa Nacional de Administração Pública (PNAP), da Universidade Estadual do Centro-Oeste - UNICENTRO. Para isso, utilizou-se como metodologia a pesquisa exploratória e descritiva, bem como a quantitativa. Para a coleta de dados optou-se pela aplicação de questionários, o qual teve a participação de 72 acadêmicos dos oito polos, envolvendo os três cursos do PNAP, os quais são a Gestão Pública, Gestão Pública Municipal e Gestão da Saúde, além de 50 tutores presenciais e a distância. Com base na análise das informações coletadas, verificou-se que há altos índices de satisfação, tanto de acadêmicos quanto de tutores. Também pode-se perceber que há uma preocupação em manter a qualidade de ensino dos cursos, já que tutores e professores estão atendendo de forma adequada e rápida às solicitações dos acadêmicos.

Palavras-chave: Educação a distância. PNAP. Satisfação. Qualidade.

\section{SATISFACTION EVALUATION IN DISTANCE EDUCATION SPECIALIZATION PROGRAMS: THE PONT OF VIEW OF TUTORS AND ACADEMICS OF PNANP/UAB}

Abstract: This study originated from a research that had as objective to analyze the satisfaction with the specialization's program of the National Program of Public Management (PNAP), of Universidade Estadual do Centro-Oeste - UNICENTRO, from the point of view of academics and tutors. For that, a descriptive and exploratory as well as the quantitative research was used as methodology. For the data collection questionnaires were applied, which had the participation of 72 academics of the eight poles, involving the three programs of PNAP, which are Public Management, Municipal Public Management and Health Management, besides the 50 on site and distance tutors. With the analysis of the collected information, it was verified that there are high rates of satisfaction for both, academics and tutors. It could also seen that there is a concern to maintain the quality of education, since that tutors and professors are answering appropriately and promptly to the requests of academics.

Key words: Distance education. PNAP. Satisfaction. Quality. 


\section{INTRODUÇÃO}

No Brasil, a educação a distância (EaD) é uma modalidade de ensino que vem crescendo gradativamente, já que ela proporciona uma alternativa de estudar sem necessariamente estar presente em sala de aula, pois a $\mathrm{EaD}$ utiliza como principal meio de comunicação o correio, a internet, rádio, televisão. Isso se verifica com o crescimento das matrículas realizadas nos cursos a distância, que obtiveram um aumento de $96.9 \%$ entre 2007 e 2008 (AGÊNCIA DO BRASIL, 2009).

Como afirma Moran (2007), as pessoas aprendem de maneira mais flexível quando estão conectadas em rede, por meio de grupos de interesse, programas de comunicação instantânea. Dessa forma, a Educação a Distância vem se destacando cada vez mais, fazendo com que as pessoas obtenham acesso de forma mais fácil e com melhores recursos de aprendizado do que poderiam a alguns anos atrás, quando era possível ter acesso apenas a cursos oferecidos localmente (MOORE; KEARSLEY, 2007).

Outro aspecto importante é que, independente do ramo em que se encontra a organização, é importante para sua sobrevivência atenção para imagem, ou seja, a percepção que as pessoas envolvidas com a organização possuem desta. Dentro de uma instituição de ensino, a imagem influencia, direta ou indiretamente, a qualidade do ensino, visto que de acordo com a percepção que o docente possui da instituição, poderá possuir um maior ou menor comprometimento (NEVES, RAMOS, 2008).

Considerando que a Universidade Estadual do Centro-Oeste, oferece cursos nessa modalidade, o problema de pesquisa consiste em verificar qual o grau de satisfação de acadêmicos e tutores em relação ao andamento dos cursos a distância do PNAP - (Programa Nacional de Administração Pública), considerando que tais cursos tiveram início no ano de 2010.

Dessa forma, esse artigo tem como objetivo analisar a satisfação dos alunos e tutores, bem como suas expectativas em relação aos cursos do Programa Nacional de Administração Pública (PNAP), da Universidade Estadual do Centro-Oeste (UNICENTRO).

Quanto a sua estrutura, esse artigo se inicia com o referencial teórico, no qual se apresenta um breve histórico da Educação a Distância, as principais modalidades de ensino a distancia e a satisfação nos serviços de ensino. Após esse referencial, é apresentada a metodologia de pesquisa, bem como a análise da pesquisa de campo, os resultados obtidos e considerações finais. 


\section{REFERENCIAL TEÓRICO}

\subsection{Ensino a Distância}

\section{Quadro 1 - Características da EaD}

\begin{tabular}{|c|c|}
\hline Característica & Descrição \\
\hline $\begin{array}{l}\text { Separação professor/ } \\
\text { aluno }\end{array}$ & A distância existente entre eles impede o contato direto. \\
\hline Sistema Multimídia & $\begin{array}{l}\text { Devido à distância que se encontram os professores e alunos, não há } \\
\text { possibilidade de relação didática entre eles. Assim, há a necessidade } \\
\text { de suprir a ação do docente do docente por meio do uso de outras } \\
\text { vias. }\end{array}$ \\
\hline $\begin{array}{l}\text { Aprendizagem } \\
\text { autônoma }\end{array}$ & $\begin{array}{l}\text { Na EaD, o aluno deve aprender a estudar sozinho, sendo a razão } \\
\text { principal pelo qual muitos escolhem a EaD, pelo fato de poder optar } \\
\text { quando e onde quer estudar. }\end{array}$ \\
\hline $\begin{array}{l}\text { Organização de } \\
\text { suporte }\end{array}$ & $\begin{array}{l}\text { Toda a estrutura da EaD estará voltada a proporcionar aos alunos os } \\
\text { recursos necessários, como material didático, equipe de professores, } \\
\text { biblioteca. }\end{array}$ \\
\hline $\begin{array}{l}\text { Comunicação } \\
\text { bidirecional }\end{array}$ & $\begin{array}{l}\text { Como não se pode ter uma reação imediata do aluno, há a } \\
\text { necessidade de multiplicar as formas de receber as respostas, como } \\
\text { o telefone, carta, e-mail, fax, vídeo conferência, teleconferência e } \\
\text { também os momentos que são presenciais. }\end{array}$ \\
\hline $\begin{array}{l}\text { Procedimentos } \\
\text { industriais e efeito } \\
\text { multiplicador }\end{array}$ & $\begin{array}{l}\text { Na EaD deve ser tudo planejado com tempo, pois não há tempo para } \\
\text { improvisações. }\end{array}$ \\
\hline Economia & $\begin{array}{l}\text { Após confeccionados os materiais, os gastos podem ser divididos } \\
\text { entre exemplares e usuários, resultando um uma economia patente. } \\
\text { O professor é o que poderá sair mais caro, mas este é contratado por } \\
\text { tempo limitado. }\end{array}$ \\
\hline $\begin{array}{l}\text { Comunicação em } \\
\text { massa }\end{array}$ & $\begin{array}{l}\text { A comunicação nos cursos da EaD é dirigida a um grande número de } \\
\text { pessoas, podendo ter um impacto massivo }\end{array}$ \\
\hline $\begin{array}{l}\text { Reposta às } \\
\text { demandas sociais }\end{array}$ & $\begin{array}{l}\text { É frequente a oferta de cursos da atualidade, os quais estão impondo- } \\
\text { se como panorama cultura e social }\end{array}$ \\
\hline $\begin{array}{l}\text { Conversa didática } \\
\text { interativa }\end{array}$ & Os materiais devem facilitar o estudo autônomo. \\
\hline Flexibilidade & $\begin{array}{l}\text { Devido às variadas situações que podem se encontrar os alunos, } \\
\text { é necessário reduzir a rigidez administrativa, proporcionando } \\
\text { flexibilidade de tempo, lugar, materiais e recursos ao professor. }\end{array}$ \\
\hline Tutoria & $\begin{array}{l}\text { Na EaD a maiorias das tarefas dos professores são assumidos pelo } \\
\text { material didático, sendo o professor tutor a pessoa mais próxima do } \\
\text { aluno, devendo estar sempre pronto a ajudar os alunos, assessorando } \\
\text { o estudo, motivando-os, apoiando em seus esforços pessoais; }\end{array}$ \\
\hline
\end{tabular}

Fonte: Arredondo (apud MAIA, 2003).

Diante do apresentado, verifica-se que os autores concordam que a EaD é um modalidade de ensino que caracteriza-se basicamente pelo fato de que professor e alunos encontrarem-se em espaços geográficos distintos. Dessa forma, necessitam de ferramentas que possibilitem a comunicação entre eles, 
como o correio, rádio, televisão e internet. Essas ferramentas são resultados da evolução que a EaD sofre ao longo de sua implementação, assim como as ferramentas utilizadas nessa modalidade.

A seguir, apresenta-se no quadro 2 as gerações do ensino a distância, os meios de comunicação utilizados pelas instituições e bem como as principais características de cada uma.

\section{Quadro 2 - Gerações da EaD}

\begin{tabular}{|c|c|c|}
\hline Geração & Meio de Comunicação & Características \\
\hline $1^{\mathrm{a}}$ & Correspondência & $\begin{array}{l}\text { A principal característica dessa geração é o intercâmbio de } \\
\text { documentos. Desde o surgimento da escrita até a década } \\
\text { de } 1880 \text {, a modalidade de ensino que se dissemina é cha- } \\
\text { mada de Estudo por Correspondência, onde a comunica- } \\
\text { ção era feita por meio de textos escritos, e posteriormente, } \\
\text { com impressos. }\end{array}$ \\
\hline $2^{\underline{a}}$ & Rádio e TV & $\begin{array}{l}\text { Com início no século XX, era transmitida via rádio e tele- } \\
\text { visão. Sendo a rádio com autorização para uma emissora } \\
\text { educacional em 1921, e a televisão, em } 1934 \text { a TV Educa- } \\
\text { tiva estava em desenvolvimento (SPANHOL apud LENZI, } \\
\text { 2010) }\end{array}$ \\
\hline $3^{\mathrm{a}}$ & $\begin{array}{l}\text { Áudio, Vídeo e } \\
\text { Correspondência }\end{array}$ & $\begin{array}{l}\text { Final da década de } 1960, \text { tem-se início as Universidades } \\
\text { Abertas, as quais faziam uso de áudio e vídeo, além da } \\
\text { correspondência e da orientação face-a-face, por meio de } \\
\text { equipes de cursos. }\end{array}$ \\
\hline $4^{\mathrm{a}}$ & $\begin{array}{l}\text { Computador, } \\
\text { Teleconferência, Áudio } \\
\text { e Videoconferência }\end{array}$ & $\begin{array}{l}\text { Em meados dos anos } 80 \text {, a EaD passa a utilizar telecon- } \\
\text { ferências por áudio, vídeo e computador, possibilitando a } \\
\text { interação síncrona entre alunos, professore e instrutores. }\end{array}$ \\
\hline $5^{\mathrm{a}}$ & Internet e Web & $\begin{array}{l}\text { Essa Geração veio com o desenvolvimento da internet, } \\
\text { com possibilidade de se ter classes virtuais, utilizando mé- } \\
\text { todos construtivistas, integrando textos, áudio e vídeo em } \\
\text { uma plataforma. }\end{array}$ \\
\hline
\end{tabular}

Fonte: adaptado de Moore e Kearsley (apud LENZI, 2010)

A evolução da EaD é acompanhada pelo aprimoramento dos meios de comunicação, o que facilita a transmissão das informações, bem como possibilita um melhor relacionamento entre o professor e alunos.

\subsection{Modalidades de Ensino à Distância}

A EaD pode, segundo Rodrigues e Barcia (1998), assumir várias formas, além de ser promovida por várias instituições com objetivos diferentes, exem- 
plificando, um dos fatores que indicam a estrutura disponível é a recepção. Conforme Vianney et al (apud RODRIGUES; BARCIA, 1998) é na recepção que concretiza-se a aprendizagem, com a utilização de diferentes meios.

Saraiva (apud RODRIGUES; BARCIA, 1998) separa a recepção nas seguintes modalidades:

\section{Quadro 3 - Modalidades de Recepção}

\begin{tabular}{|c|c|}
\hline Modalidade & Descrição \\
\hline Livre & $\begin{array}{l}\text { Com recepção de forma individual, com clientela ilimitada, diversificada e não } \\
\text { definida previamente. Exemplo: Programas informativo-culturais }\end{array}$ \\
\hline Isolada & $\begin{array}{l}\text { A pessoa inscreve-se no programa ou curso e recebe a mensagem, podendo } \\
\text { ser por meio do rádio, televisão, impressa ou computador. Ela deve estudar } \\
\text { sozinha e submeter-se a uma avaliação fora do processo, sendo o material } \\
\text { impresso indispensável para os alunos. Controla-se pelo número de inscritos } \\
\text { e pela distribuição do material. Exemplo: Telecurso 2000, da Fundação Ro- } \\
\text { berto Marinho. }\end{array}$ \\
\hline Controlada & $\begin{array}{l}\text { Este permite o acompanhamento, controle e avaliação dos inscritos, não ne- } \\
\text { cessariamente em um mesmo local. Com encontros periódicos, uma equipe } \\
\text { reúne-se com os alunos para resolver problemas, tirar dúvidas, orientações. } \\
\text { Esse auxílio, denominado Tutoria, pode ser realizado à distância, por meio do } \\
\text { correio, telefone, fax. A avaliação é contínua. Exemplo: a maioria das Univer- } \\
\text { sidades Abertas. }\end{array}$ \\
\hline Integrada & $\begin{array}{l}\text { Esta modalidade é onde a programação (radiofônica, televisiva, computa- } \\
\text { dorizada) integra-se às atividades educativas, prestando aopio, reforço e/ou } \\
\text { enriquecimento. Existe uma estrutura montada (salas de aula). Exemplo: pro- } \\
\text { gramas de TV Escola e o uso de Internet nas escolas. }\end{array}$ \\
\hline Organizada & $\begin{array}{l}\text { Tem como principal característica a presença constante e permanente do } \\
\text { orientador de aprendizagem, dinamizando e orientando as atividades da tele- } \\
\text {-sala, facilitando a aprendizagem. Ele também exerce a mediação pedagógi- } \\
\text { ca, controle e avaliação. Exemplo: Programa Salto para o Futuro. }\end{array}$ \\
\hline Informatizada & $\begin{array}{l}\text { Alunos recebem os materiais modelados especialmente para os cursos, ma- } \\
\text { teriais impressos, vídeo, CD-ROMs, e interação em tempo real por meio de } \\
\text { chats com o professor e alunos. Os trabalhos, avaliações, seminários são } \\
\text { todos conduzidos pela Internet, por meio de ferramentas disponíveis nos equi- } \\
\text { pamentos. Pode também haver encontros presenciais. Exemplo: especializa- } \\
\text { ções para Gestores de Instituições de Ensino Técnico. }\end{array}$ \\
\hline Interativa & $\begin{array}{l}\text { Aulas são feitas fazendo uso de vídeo conferências, no qual alunos e pro- } \\
\text { fessor podem comunicar-se em tempo real. Os encontros presenciais são } \\
\text { raros, e os trabalhos, avaliações e orientações são feitos durante as aulas, } \\
\text { que exploram o potencial dos periféricos. Tais periféricos permitem a apresen- } \\
\text { tação de vídeos, documentos e imagens de computador. Exemplo: cursos de } \\
\text { mestrado, como o promovido pela UFSC, Gestão Tecnológica dos Alunos da } \\
\text { Equitel e Logística da Petrobrás. }\end{array}$ \\
\hline
\end{tabular}

Fonte: adaptado de Vianney (apud RODRIGUES; BARCIA, 1998) 
A EaD tem trazido experiências de sucesso em todo o mundo, principalmente após passarem a utilizar as novas tecnologias, como o aparecimento da fibra ótica, comunicação via satélite, Internet, vídeos e teleconferências, acarretando na expansão da aprendizagem virtual (MELO; MELO; NUNES, 2009).

A educação a distância caracteriza, basicamente, por um cenário educacional onde instrutor e alunos estão separados pelo tempo e/ou posição. A EaD fazem uso de diversos meios de comunicação, com o intuito de permitir sua viabilidade, como por exemplo, correspondência escrita, texto, gráficos, áudio, fita de vídeo, CD-ROM, videoconferência, televisão interativa, fax, e-mail, entre outros (MAIA, MEIRELLES, 2005).

De acordo com Takahashi (2006), da Folha de São Paulo, um estudo patrocinado pelo Ministério da Educação (MEC), o material impresso é o meio mais utilizado pelo ensino a distância, com $84,7 \%$. O e-learning, ou seja, a internet, está logo atrás, com $61,2 \%$, e o CD-Rom, com $41,8 \%$, sendo que a soma será superior a $100 \%$ devido a uma mesma instituição poder utilizar mais de uma mídia como método de aprendizagem.

Silva e Barros (2008) citam outras ferramentas de comunicação que são utilizadas como meios de transmissão de informações, os quais são o e-mail, chat e fórum de discussões.

Para Pallof e Pratt (apud OLIVEIRA; DOMINGUES, 2008), a Internet proporciona diversos recursos de comunicação, os quais estão sendo utilizados como tecnologias educacionais. Entre os mais comuns, estão os fóruns, chat (bate-papo), blogs, listas de discussão, web conferências, comunidades virtuais.

Com isso, nota-se que há diferentes tipos de $\mathrm{EaD}$, assim como meios que permitem a comunicação e interação entre professor, tutores e acadêmicos, destacando a importância que a internet possui para a evolução dos cursos a distância, já que criou uma maior facilidade para a comunicação entre as pessoas.

\subsection{Satisfação em Serviços de Ensino}

A satisfação pode ser definida como sendo, conforme Kotler (2000) o nível de sentimento de um indivíduo, que é resultado da comparação do desempenho/resultado de um produto/serviço em relação às suas expectativas.

No Japão, a corrente de trabalho fez-se com que a qualidade com a excelência no atendimento ao cliente fosse relacionada com a satisfação do consumidor (CARVALHO NETO, 2009). 
Com os clientes e/ou consumidores mostrando-se cada vez mais exigentes e informados, as organizações e instituições estão procurando fazer quase o impossível para satisfazer esse novo público, buscando meios que possibilitem a satisfação, fidelização e o encantamento de seus clientes e/ou consumidores (FORTES et al, 2007)

Conforme Fonseca e Borges Jr. (apud ONUSIC, 2009), há três determinantes da satisfação, os quais são a qualidade percebida, o valor percebido e as expectativas. A primeira, qualidade percebida, está relacionada à performance da organização e a sua capacidade de atender as necessidades dos consumidores. O valor percebido é a qualidade da oferta e o preço praticado. E por último, as expectativas são associadas o conhecimento acumulado sobre a qualidade das ofertas do fornecedor.

Dessa forma, Boone e Kurtz (apud ONUSIC, 2009) a satisfação do cliente vem da capacidade de um serviço e/ou produto em atender ou exceder as necessidades e expectativas do comprador. Para isso, segundo Fortes (2007), para que as organizações que prestam serviços seja bem sucedida, é importante que ela conheça seus clientes, buscando conhecer quais são os principais gostos e anseios dos seus consumidores, suas preferências, necessidades, aspirações ocultas, pois será somente após entender seus clientes, que as organizações atingirão o ponto certo. Ainda, a autora afirma que a qualidade nos serviços prestados é um fator que pode proporcionar ao seu prestador a fidelização dos clientes, criando uma vantagem competitiva diante de seus concorrentes.

De acordo com autores como Parasuraman et al, Grönroos (apud CARVALHO NETO, 2009), a percepção da qualidade dos produtos ou serviços prestados pode ser analisada pela diferença entre a qualidade esperada pelo consumidor/cliente antes de adquiri-lo, e a qualidade identificada após a compra do produto ou contratação do serviço.

Alguns aspectos que devem ser analisados em instituições de ensino, para que se tenha a satisfação de seus clientes, é a acessibilidade, o atendimento, a capacitação do Corpo Docente, comunicação, o conteúdo das disciplinas, a credibilidade, infra-estrutura, entre outros (CARVALHO NETO, 2009).

De acordo com Waters $(2007$, p. 2) a satisfação do cliente e a qualidade do serviço estão integralmente relacionados, e embora da faculdade não esteja preocupada com a lucratividade, eles estão preocupados com a retenção ${ }^{1}$.

1 Customer satisfaction and service quality are integrally related, and although the community college is not concerned about profit, they are concerned about retention. 
Para Reinert e Reinert (apud SOUZA; REINERT, 2010) os estudantes não podem ser considerados como um cliente simples, mas deve ser visto como um verdadeiro parceiro no processo de aprendizagem, ou seja, o estudante não é um produto a ser processado, muito menos um cliente que está do outro lado do balcão, deve ser atendido como um participante ativo no ensino, que possui comportamentos de um sócio em relação às escolas.

De acordo com Kotler e Fox (apud ONUSIC, 2009), a mensuração da satisfação dos discentes não é uma tarefa que se pode considerar fácil, já que as características que relacionam sua satisfação à escola são diferentes entre cada indivíduo. Ainda, nota-se que, em se tratando da educação superior, o cliente estará participando do serviço oferecido, dessa forma, caso não desempenhe bem o seu papel, afetará o resultado do serviço.

A importância em manter os clientes satisfeitos está em que, quando estes são leias à organização que lhe vende o produto ou presta o serviço, há a tendência de se engajar em propaganda boca a boca favorável à empresa (ANDERSON apud MILAN; TREZ, 2005).

Dessa forma, nota-se a importância para as instituições de ensino verificarem o grau de satisfação de seus alunos, com o intuito de conhecerem se as expectativas dos acadêmicos com relação aos cursos ofertados pela instituição está de acordo com o que era esperado pelos mesmos antes de ingressarem no curso. Para que, com isso, possam aprimorar sua metodologia de ensino, atendimento às necessidades dos estudantes, bem como trabalhar na imagem percebida da instituição.

Neste sentido, para a análise deste estudo de caso, será observado variáveis relacionadas ao domínio de conteúdo tanto por professores quanto por tutores, entendimento do conteúdo pelos acadêmicos, materiais disponibilizados para os mesmos, bem como atendimentos prestado por docentes e tutores aos acadêmicos dos cursos à distância do PNAP.

\section{METODOLOGIA}

A pesquisa abrangeu acadêmicos dos três cursos de especialização, sendo eles, Gestão Pública, Gestão Pública Municipal e Gestão em Saúde, o qual foi aplicado com o auxílio de tutores e professores dos cursos, no dia 02 de abril de 2011, já que os alunos, tutores e professores estavam presentes nos polos para aplicação de avaliação de uma disciplina. Ao total foram aplicados 72 questionários, incluiu acadêmicos dos oito polo. Considerando que há 1182 
acadêmicos cursando os três cursos, em oito cidades, optou-se por escolher aleatoriamente 3 (três) acadêmicos de cada curso, em cada polo.

Quanto aos tutores, o questionário foi aplicado pela pesquisadora no dia 09 de abril de 2011, o qual totalizou 50 respondentes, sendo que 32 são tutores presenciais e 18 são tutores a distância, os quais estavam reunidos para participarem de um curso de capacitação. Os tutores pertenciam aos três cursos de especialização oferecidos pelo PNAP, no qual há 34 tutores presenciais e 37 a distância.

Com relação à aplicação da pesquisa de campo, não houve dificuldades, já que os acadêmicos estavam no polo para a realização de uma prova do curso e os tutores estavam na Unicentro para participarem de um treinamento a UAB.

O questionário elaborado para aplicar com os tutores e alunos do PNAP foi baseado e adaptado de Fortes (2007) e de Oliveira (2006), que é o modelo de questionário utilizado para os acadêmicos e Anexo 2, modelo usado para os tutores. Tais questionários contem aspectos relacionados ao alcance dos objetivos iniciais dos cursos, preparação e domínio de conteúdo por professores e tutores, horários e atendimento dos tutores, materiais disponibilizados, ambiente Moodle webconferência e grau de satisfação com os cursos, além de informações sobre idade, sexo, escolaridade. Para os tutores, também incluiu questões relacionados à novos treinamentos e metodologia de treinamento. . Tais questões tiveram como objetivo verificar o grau de satisfação que os acadêmicos e tutores estão com os cursos do PNAP, bem como a qualidade que está sendo oferecido por esses cursos.

A ANOVA consiste em formular duas Hipóteses. A hipótese inicial, denominada $\mathrm{H}_{0}$ em que se admite que as médias de satisfação dos três cursos são iguais contra a hipótese alternativa $\mathrm{H}_{1}$, onde existem diferenças entre pelo menos uma das 3 médias. Para verificação das hipóteses é necessário calcular o valor de $F$, chamado $F$ calculado, e compará-lo com o $F$ tabelado (ou crítico). O $F$ tabelado para nível de significância $5 \%=0,05$ é de 2,1564 , com graus de liberdade 7 e 64 . Valores de $F$ calculado acima de 2,1564 ou abaixo de -2,1564 indicam que existe diferenças significativas entre as médias de satisfações nos cursos. Pode-se também analisar a existência ou não de diferenças significativas comparando-se o valor de $p$ calculado com o valor do nível de significância adotado. Caso $p$ calculado apresente valor maior que 0,05 fica evidente a presença de diferenças significativas, em caso contrário elas não existem.

O quadro 4 resume os testes utilizados para análise dos resultados obtidos com a pesquisa de campo. 


\section{Quadro 4 - Técnicas, Objetivos d Finalidades de Pesquisa}

\begin{tabular}{|c|c|c|}
\hline Técnica & Objetivo da Técnica & Finalidade da Aplicação \\
\hline $\begin{array}{l}\text { Pesquisa } \\
\text { exploratória }\end{array}$ & $\begin{array}{l}\text { Rodrigues (2007) define o objetivo da pesqui- } \\
\text { sa exploratória como sendo a caracterização } \\
\text { inicial, ou seja, constitui a primeira etapa de } \\
\text { toda pesquisa científica, o qual deverá propor- } \\
\text { cionar um maior entendimento do problema, a } \\
\text { realização de um levantamento bibliográfico } \\
\text { e de entrevistas. }\end{array}$ & $\begin{array}{l}\text { Levantamento bibliográfico do } \\
\text { assunto a ser tratado na pesquisa } \\
\text { de campo. }\end{array}$ \\
\hline $\begin{array}{l}\text { Pesquisa } \\
\text { descritiva }\end{array}$ & $\begin{array}{l}\text { Ainda de acordo com Rodrigues (2007) } \\
\text { esta pesquisa tem como objetivo observar, } \\
\text { registrar, analisar, interpretar os fatos, sem a } \\
\text { interferência do pesquisador. característica } \\
\text { da descritiva é o fato de se coletar dados por } \\
\text { meio de técnicas padronizadas, como ques- } \\
\text { tionários e observação sistêmica. }\end{array}$ & $\begin{array}{l}\text { Conhecer a visão de acadêmicos } \\
\text { e tutores sobre os cursos de es- } \\
\text { pecialização do PNAP. }\end{array}$ \\
\hline $\begin{array}{l}\text { Pesquisa } \\
\text { Quantitativa }\end{array}$ & $\begin{array}{l}\text { Roesch (2007) tem como propósito mensurar } \\
\text { as relações entre variáveis, avaliação de re- } \\
\text { sultado de um projeto. As principais técnicas } \\
\text { usadas para coleta de dados são os questio- } \\
\text { nários, testes, observação e entrevista. }\end{array}$ & $\begin{array}{l}\text { Analisar o grau de satisfação de } \\
\text { acadêmicos e tutores em seu } \\
\text { primeiro ano após a implantação, } \\
\text { por meio de aplicação de ques- } \\
\text { tionários. }\end{array}$ \\
\hline $\begin{array}{l}\text { Lançamento } \\
\text { dos dados } \\
\text { em planilha } \\
\text { do Excel }\end{array}$ & $\begin{array}{l}\text { Analisar todos os dados coletados com a } \\
\text { pesquisa de campo. }\end{array}$ & $\begin{array}{l}\text { Análise das informações coleta- } \\
\text { das, o qual possibilitou a sepa- } \\
\text { ração em dois blocos de dados, } \\
\text { sendo as respostas das perguntas } \\
\text { transformadas em escala Likert } \\
\text { de } 1 \text { à } 5 \text { para propiciar caráter } \\
\text { quantitativo. }\end{array}$ \\
\hline $\begin{array}{l}\text { Análise de } \\
\text { Variância ou } \\
\text { ANOVA }\end{array}$ & $\begin{array}{l}\text { Marques (2004) afirma que é o principal teste } \\
\text { paramétrico envolvendo } k(k>2) \text { amostras, } \\
\text { o qual testa diferença de médias para } k \\
\text { amostras independentes. Esse tipo de teste } \\
\text { permite a comparação entre três ou mais } \\
\text { amostras, para testar a existência, simultânea, } \\
\text { de diferença significativa entre três ou mais } \\
\text { grupos originários da mesma população ou } \\
\text { de população idênticas. }\end{array}$ & $\begin{array}{l}\text { Detectar possíveis diferenças } \\
\text { estatisticamente significativas nas } \\
\text { variáveis (entre os três cursos - } \\
\text { Gestão da Saúde, Gestão Pública } \\
\text { e Gestão Pública Municipal, e } \\
\text { também entre os oito polos) por } \\
\text { meio do ANOVA, e pelo teste } t \\
\text { para comparação entre tutores a } \\
\text { distância e presenciais. }\end{array}$ \\
\hline
\end{tabular}

Fonte: Elaborado pelos autores.

\section{ANÁLISE DE DADOS E RESULTADOS}

\subsection{Caso da IES Analisada}

A Universidade Aberta do Brasil (UAB) foi criada pelo Ministério da Educação em 2005, em parceria com a ANDIFES (Associação Nacional dos Dirigentes das Instituições de Ensino Superior) e de Empresas Estatais, tendo como foco a Educação Política e a Gestão da Educação Superior (UAB, 2011). A UAB é um sistema integrado pelas universidades públicas, os quais oferecem cursos de nível superior, fazendo uso de metodologia da educação a distância, 
e que tem a finalidade de expandir e interiorizar a oferta de programas e cursos a distância no País. Assim, este sistema proporciona a articulação, interação e efetivação de iniciativas para estimular a parceria entre os três governos, federal, estadual e municipal, com as universidades públicas e demais organizações.

De acordo com o site da UAB, atualmente, há 88 instituições que fazem parte do Sistema UAB, sendo as universidades federais, estaduais, Institutos Federais de Educação, Ciência e Tecnologia (IFETs). Em 2009, o Sistema já contava com 720 polos de apoio presencial aprovados e instalados, com criação de 187.154 vagas nos diversos cursos.

A Universidade Estadual do Centro-Oeste (UNICENTRO) possui cursos da Educação a Distância desde 2005, estando a UAB/Unicentro vinculada ao Núcleo de Educação a Distância. Em 2006, foi aprovado os primeiros cursos, sendo eles, a Graduação em História e a Especialização em Gestão Escolar (UAB/UNICENTRO, 2011). Posteriormente, foi aprovada para ofertar os cursos de aperfeiçoamento em Educação de Jovens e Adultos e o aperfeiçoamento em educação, Diversidade e Cidadania.

Recentemente, a Unicentro foi selecionada para o desenvolvimento e a execução de novos cursos, os quais estavam vinculados ao Programa Nacional de Administração Pública (PNAP), sendo oferecido os cursos em: Graduação em Administração Pública, Especialização em Gestão Pública, Especialização em Gestão Pública Municipal e Especialização em Gestão em Saúde.

De acordo com o CAPES (2011), os cursos do PNAP "tem como objetivo a formação e qualificação de pessoal em nível superior visando ao exercício de atividades gerenciais e do Magistério Superior".

$\mathrm{Na}$ Unicentro, os cursos vinculados ao PNAP estão presentes em 8 polos no Paraná, sendo as cidades de Apucarana, Bituruna, Flor da Serra do sul, Laranjeiras do Sul, Nova Tebas, Palmital, Pato Branco e Pinhão, os quais totalizam 400 vagas por polo.

Para este caso, será considerado os cursos oferecidos pelo PNAP, da Unicentro, o qual envolverá os cursos três especialização, Gestão Pública, Gestão Pública Municipal e Gestão em Saúde. A pesquisa será com acadêmicos desses cursos, além dos tutores a distância e presenciais dos mesmos.

\subsection{Análise da Pesquisa de Campo}

Neste item serão expostos e analisados os resultados obtidos com a pesquisa de campo realizado com os acadêmicos e tutores dos cursos a distância do PNAP, Unicentro. 


\subsubsection{Acadêmicos - Análise dos Dados Gerais}

Nesta etapa do estudo será realizada uma análise das informações coletas a partir da pesquisa de campo realizada por meio da aplicação de questionários com os acadêmicos e tutores dos cursos a distância do PNAP.

A Tabela 1 expõe as informações referente à idade, sexo e escolaridade dos acadêmicos que estão cursando as especializações em Gestão Pública, Gestão Pública Municipal e Gestão em Saúde.

Tabela 1 - Dados Gerais da Pesquisa de Campo com os Acadêmicos

\begin{tabular}{cccc}
\hline Variável & Escala & N & $\%$ \\
\hline \multirow{3}{*}{ Idade } & 21 A 25 anos & 15 & 20,83 \\
& 26 A 30 anos & 17 & 23,61 \\
& 31 A 35 anos & 13 & 18,06 \\
\cline { 2 - 4 } & 36 A 40 anos & 6 & 8,33 \\
\multirow{2}{*}{ Gênero } & 41 anos ou mais & 21 & 29,17 \\
& Masculino & 24 & 33,33 \\
& Feminino & 48 & 66,67 \\
\hline \multirow{3}{*}{ Escolaridade } & Superior Completo & 21 & 29,17 \\
& Especialização Incompleta & 25 & 34,72 \\
& Especialização Completa & 26 & 36,11 \\
& Mestrado & 0 & 0,00 \\
\hline
\end{tabular}

Fonte: Elaborado pelos autores, por meio dos dados coletados

Legenda: $\mathrm{N}$ = ao número de acadêmicos pesquisados; e \% percentual referente ao número de acadêmicos pesquisados.

Com base na Tabela 1, nota-se que a maior parte das pessoas que optam por ingressar em um curso a distância do PNAP da Unicentro, estão entre as idades de 21 e 30 anos, com 43,93\%. Porém, também verifica-se que 37,5\% são indivíduos com mais de 36 anos, o qual percebe-se que cursos a distância podem criar a oportunidade para que estas pessoas voltem a estudar, oferecendo-lhes a opção de obterem um curso de especialização.

Ainda na Tabela 1, evidencia-se que entre os 72 acadêmicos pesquisados, dois terços deste representam mulheres.

Quanto ao grau de escolaridade das pessoas, verificou-se que aproximadamente $70 \%$ possuem ou uma especialização completa, ou uma especialização 
incompleta, o que demonstra que tais cursos a distância tem como perfil acadêmico aqueles indivíduos que procuram por uma pós-graduação mais específica.

\subsubsection{Tutores - Análise dos Dados Gerais}

Com os questionários aplicados ao tutores presenciais e tutores a distância pode-se notar na Tabela 2 que $65 \%$ dos respondentes possuem entre 21 e 30 anos. Além disso, é possível verificar que a maiorias dos tutores pertencem ao sexo feminino, onde tem-se 31 mulheres do total de 50 respondentes.

Tabela 2 - Dados Gerais da Pesquisa de Campo com os Tutores a Distância e Tutores Presenciais

\begin{tabular}{cccccc}
\hline \multirow{2}{*}{ Variável } & \multirow{2}{*}{ Escala } & \multicolumn{2}{c}{ Tutores a Distância } & \multicolumn{2}{c}{ Tutores Presenciais } \\
\cline { 2 - 6 } & & No & \% & No & \% \\
\hline \multirow{5}{*}{ Idade } & 21 A 25 anos & 4 & 22,22 & 4 & 12,50 \\
\cline { 2 - 6 } & 26 A 30 anos & 7 & 38,89 & 18 & 56,25 \\
\cline { 2 - 6 } & 31 A 35 anos & 2 & 11,11 & 6 & 18,75 \\
\cline { 2 - 6 } Gênero & 36 A 40 anos & 2 & 11,11 & 1 & 3,13 \\
& 41 anos ou mais & 3 & 16,67 & 3 & 9,38 \\
\hline \multirow{4}{*}{ Escolaridade } & Masculino & 7 & 38,89 & 12 & 37,50 \\
& Feminino & 11 & 61,11 & 20 & 62,50 \\
\cline { 2 - 6 } & Especialização Incompleta & 0 & 0,00 & 0 & 0,00 \\
\cline { 2 - 6 } & Especialização Completa & 12 & 66,67 & 31 & 96,00 \\
\cline { 2 - 6 } & Mestrado & 6 & 33,33 & 1 & 3,13 \\
\hline
\end{tabular}

Fonte: Elaborado pelos autores, por meio dos dados coletados

Legenda: $\mathrm{N}=$ número de tutores pesquisados; e \% percentual referente ao número de tutores.

Ainda de acordo com a Tabela 2, verifica-se que a escolaridade dos tutores, $81,77 \%$ possuem especialização completa, e os demais possuem mestrado, o que pode-se perceber que os cursos do PNAP exigem que os tutores estejam bem preparados e com conhecimentos para que possam atender adequadamente os acadêmicos.

\subsubsection{Análise Estatística}

A primeira ANOVA foi realizada para os três cursos de pós-graduação: Gestão em Saúde, Gestão Pública Municipal e Gestão Pública. A seguir apresenta-se as tabelas que descrevem os resultados obtidos. 
Tabela 3 - Média e Variância na Anova realizada entre os grupos Gestão em Saúde, Gestão Pública Municipal e Gestão Pública

\begin{tabular}{lcccc}
\hline Grupo & Contagem & Soma & Média & Variância \\
\hline 4,304347826 & 23 & 97,82609 & 4,253308 & 0,276276 \\
\hline 4,782608696 & 23 & 97,91304 & 4,257089 & 0,315331 \\
\hline 4,086956522 & 23 & 95,30435 & 4,143667 & 0,689197 \\
\hline
\end{tabular}

Fonte: Os autores.

Anova: fator único

Tabela 4 - Valores de p e de F crítico na Anova realizada entre os grupos Gestão em Saúde, Gestão Pública Municipal e Gestão Pública

\begin{tabular}{lccccccc}
\hline Fonte da variação & $S Q$ & $g l$ & $M Q$ & $F$ & valor-P & F crítico \\
\hline Entre grupos & 0,190899 & 2 & 0,095449 & 0,223569 & 0,800263 & 3,135917935 \\
\hline Dentro dos grupos & 28,17769 & 66 & 0,426935 & -- & -- & -- \\
\hline Total & 28,36859 & 68 & --- & --- & --- & --- \\
\hline
\end{tabular}

Fonte: Os autores.

Como $F$ calculado $(=0,224)$ apresentou valor menor do que $F$ crítico $(=3,136)$, conclui-se que não se deve rejeitar a hipótese nula, ou seja, não existe diferenças significativas entre as satisfações médias entre os três grupos analisados. Ratificando a análise de $F$, pode ser analisado também o valor de $p$ calculado $(=0,800)$, maior do que o nível de significância alfa $(=0,05)$, confirmando a não rejeição da hipótese inicial.

A segunda ANOVA foi realizada com as médias dos oito polos observados da tabela 5 .

Tabela 5 - Médias de respostas dos alunos nos oito polos pesquisados

\begin{tabular}{ccccccccc}
\hline & Apucarana & \multicolumn{2}{c}{ Bituruna Flor da Ser. do Sul } & Lar. do Sul Nova Tebas & Palmital & P. Branco & Pinhão \\
\hline 1 & 4,304 & 4,261 & 4,391 & 4,826 & 3,739 & 4,478 & 4,391 & 3,565 \\
\hline 2 & 4,565 & 3,826 & 4,522 & 4,217 & 4,000 & 4,739 & 4,435 & 3,957 \\
\hline 3 & 3,609 & 4,348 & 3,870 & 4,739 & 3,174 & 4,435 & 4,478 & 4,043 \\
\hline 4 & 4,783 & 4,870 & 4,304 & 4,652 & 4,217 & 4,174 & 4,826 & 3,913 \\
\hline 5 & 3,522 & 4,087 & 4,696 & 4,870 & 3,000 & 4,696 & 4,826 & 4,043 \\
\hline 6 & 2,913 & 4,957 & 4,826 & 4,696 & 3,739 & 4,652 & 4,087 & 4,261 \\
\hline 7 & 4,087 & 4,522 & 4,826 & 4,391 & 3,000 & 4,826 & 3,522 & 4,348 \\
\hline 8 & 4,565 & 4,609 & 4,870 & 4,696 & 3,565 & 1,043 & 4,435 & 4,696 \\
\hline 9 & 4,478 & 4,783 & 3,304 & 3,522 & 3,913 & 4,696 & 4,391 & 4,609 \\
\hline
\end{tabular}

Fonte: Os autores. 
AVALIAÇÃO DA SATISFAÇÃO NO ENSINO DE PÓS À DISTÂNCIA: A VISÃO DOS TUTORES E ALUNOS DO PNAP/UAB

As tabelas 6 e 7 mostram os resultados obtidos no segundo teste.

Tabela 6 - Média e Variância na Anova realizada

entre os oito polos de pós-graduação

\begin{tabular}{lcccc}
\hline Grupo & Contagem & Soma & Média & Variância \\
\hline Apucarana & 9 & 36,8260870 & 4,0917874 & 0,38348036 \\
\hline Bituruna & 9 & 40,2608696 & 4,4734300 & 0,14198698 \\
\hline Flor da Serra do Sul & 9 & 39,6086957 & 4,4009662 & 0,27210670 \\
\hline Lar. Do Sul & 9 & 40,6086957 & 4,5120773 & 0,18089687 \\
\hline Nova Tebas & 9 & 32,3478261 & 3,5942029 & 0,19754253 \\
\hline Palmital & 9 & 37,7391304 & 4,1932367 & 1,43436253 \\
\hline P. Branco & 9 & 39,3913043 & 4,3768116 & 0,15453686 \\
\hline Pinhão & 9 & 37,4347826 & 4,1594203 & 0,12712665 \\
\hline
\end{tabular}

Fonte: Os autores.

Anova: fator único

Tabela 7 - Valores de $p$ e $F$ na Anova realizada entre os oito polos de pós-graduação

\begin{tabular}{lcccccc}
\hline \multicolumn{1}{c}{ Fonte da variação } & $S Q$ & $g l$ & $M Q$ & $F$ & valor-P & F crítico \\
\hline Entre grupos & 5,571912 & 7 & 0,7959875 & 2,2018717 & 0,045556 & 2,156423973 \\
\hline Dentro dos grupos & 23,13632 & 64 & 0,3615049 & --- & --- & --- \\
\hline Total & 28,70823 & 71 & & --- & --- & --- \\
\hline
\end{tabular}

Fonte: Os autores.

A análise da ANOVA apresentou um $F$ calculado $(=2,202)$ superior ao $F$ crítico $(=2,156)$, confirmado pelo $p$ calculado $(=0,046)$ que é menor que o valor crítico $(=0,05)$, portanto existe diferenças significativas entre as médias de satisfação dos oito polos analisados. Também foi feita a verificação, através do teste $t$, para duas amostras, em quais polos as diferenças existiam. A tabela 8 evidencia que o polo de Nova Tebas diferencia-se dos demais, ou seja, é onde existe diferença significativa de satisfação em relação aos outros polos. 


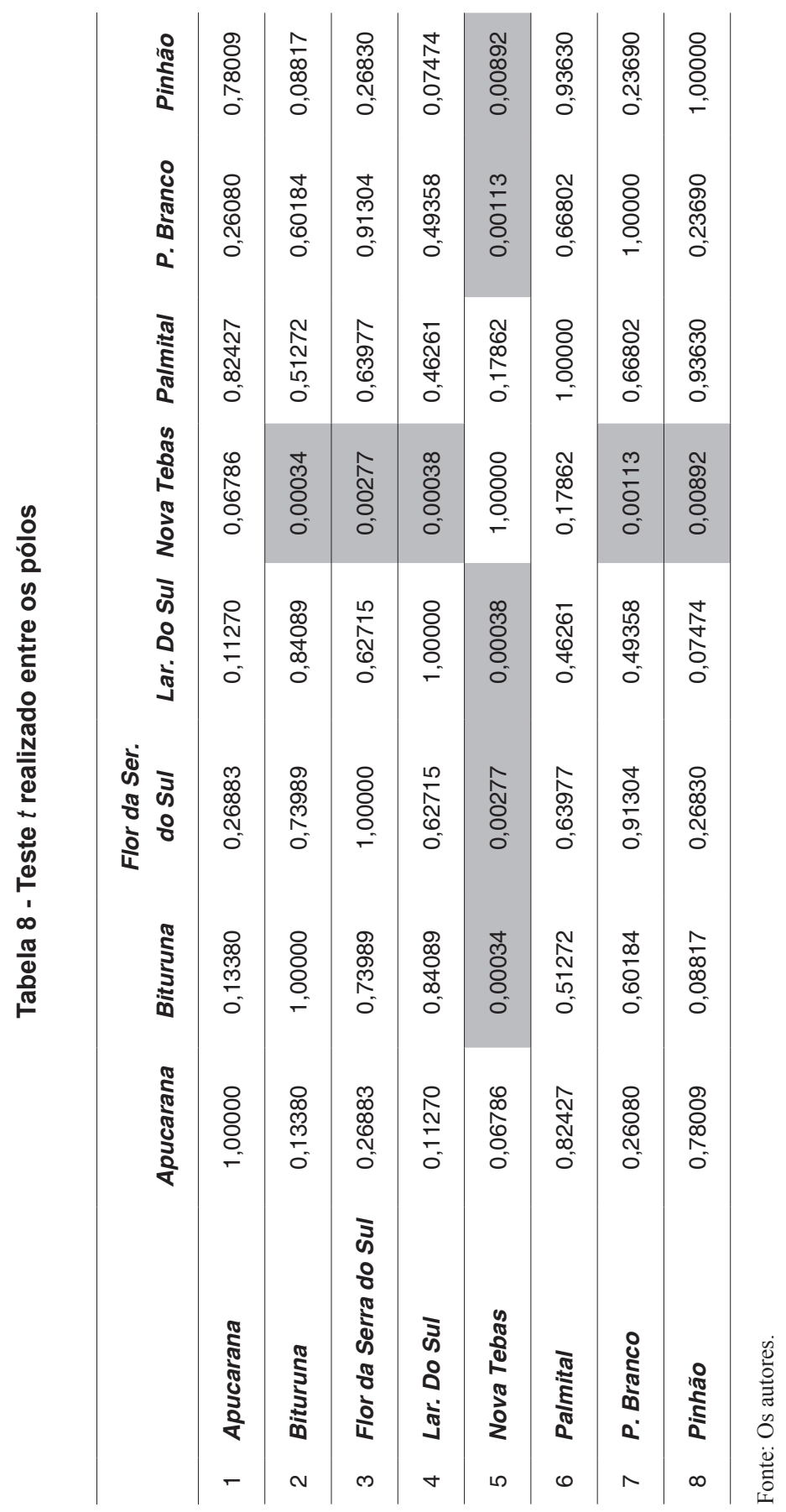


Posteriormente foi realizado o terceiro teste, para detectar se existiam diferenças significativas entre os tutores presenciais e os tutores à distância. Devido à separação entre apenas duas amostras, optou-se pela aplicação do teste $t$.

$\mathrm{O}$ teste de " $\mathrm{t}$ " consiste também em formular duas Hipóteses. A hipótese inicial, denominada $\mathrm{H}_{0}$ em que se admite que as médias entre as satisfações dos tutores presenciais e tutores a distância são iguais contra a hipótese alternativa $\mathrm{H}_{1}$, onde existem diferenças entre as médias. Optou-se por analisar a existência ou não de diferenças significativas comparando-se o valor de $p$ calculado com $o$ valor do nível de significância adotado. Caso $p$ calculado apresente valor menor que 0,05 fica evidente a presença de diferenças significativas, em caso contrário elas não existem.

Os resultados do teste estão descritos na tabela 9 a seguir.

Tabela 9 - Teste-t: duas amostras presumindo variâncias equivalentes

\begin{tabular}{lcc}
\hline & Variável 1 & Variável 2 \\
\hline Média & 4,265 & 4,316761364 \\
\hline Variância & 0,083 & 0,430883015 \\
\hline Observações & 18,000 & 32 \\
\hline Variância agrupada & 0,308 & \\
\hline Hipótese da diferença de média & 0,000 & \\
\hline Gl & 48,000 & \\
\hline Stat $t$ & $-0,316$ & \\
\hline $\mathrm{P}(\mathrm{T}<=\mathrm{t})$ uni-caudal & 0,377 & \\
\hline $\mathrm{t}$ crítico uni-caudal & 1,677 & \\
\hline $\mathrm{P}(\mathrm{T}<=\mathrm{t})$ bi-caudal & 0,754 & \\
\hline $\mathrm{t}$ crítico bi-caudal & 2,011 & \\
\hline
\end{tabular}

Fonte: Os autores.

Como o valor de $p$ calculado foi de 0,754 sendo maior que o valor de $p=0,05$, aceita-se a hipótese inicial que não existem diferenças significativas entre as satisfações dos tutores presenciais e tutores à distância.

Após a confirmação de que não existiam diferenças significativas, foi realizado um teste de ANOVA para todos os tutores, mas, separados por polos. Os dados que foram utilizados estão descritos na Tabela 10 . 
Tabela 10 - Médias de satisfações dos tutores presenciais e à distância por polo

\begin{tabular}{cccccccc}
\hline Apucarana & Bituruna & $\begin{array}{r}\text { Flor da Serra } \\
\text { do Sul }\end{array}$ & $\begin{array}{c}\text { Lar. do } \\
\text { Sul }\end{array}$ & P.Branco & Palmital & Nova Tebas & Pinhão \\
\hline 4,045 & 4,591 & 3,955 & 4,818 & 4,000 & 4,318 & 4,273 & 4,455 \\
\hline 3,773 & 4,136 & 4,455 & 4,500 & 4,182 & 4,318 & 3,682 & 4,182 \\
\hline 4,409 & 4,364 & 3,864 & 4,591 & 4,500 & 3,682 & 1,273 & 4,273 \\
\hline 4,636 & 4,500 & 4,909 & 4,409 & 3,818 & -- & -- & 4,182 \\
\hline 4,682 & 4,864 & 4,682 & 4,000 & 4,818 & -- & -- & 4,136 \\
\hline 4,273 & 5,000 & 4,091 & 4,500 & 4,773 & -- & -- & 4,591 \\
\hline 4,636 & -- & 4,455 & 4,136 & -- & -- & -- & -- \\
\hline 4,636 & -- & -- & 4,227 & -- & -- & -- & -- \\
\hline 4,273 & -- & -- & 4,864 & -- & -- & -- & -- \\
\hline-- & -- & -- & 4,773 & -- & -- & -- & - \\
\hline
\end{tabular}

Fonte: Os autores.

O resultado deste teste pode ser observado na Tabela 11 e 12 .

Tabela 11 - Média e Variância na Anova realizada entre os tutores dos oito polos de pós-graduação

\begin{tabular}{lrccr}
\hline \multicolumn{1}{c}{ Grupo } & Contagem & Soma & Média & Variância \\
\hline Apucarana & 9 & 39,363636 & 4,37374 & 0,0991 \\
\hline Bituruna & 6 & 27,454545 & 4,57576 & 0,1014 \\
\hline Flor da Serra do Sul & 7 & 30,409091 & 4,34416 & 0,1507 \\
\hline Lar. Do Sul & 10 & 44,818182 & 4,48182 & 0,0864 \\
\hline P. Branco & 6 & 26,090909 & 4,34848 & 0,1708 \\
\hline Palmital & 3 & 12,318182 & 4,10606 & 0,135 \\
\hline Nova Tebas & 3 & 9,2272727 & 3,07576 & 2,5255 \\
\hline Pinhão & 6 & 25,818182 & 4,30303 & 0,0328 \\
\hline
\end{tabular}

Fonte: Os autores.

Anova: fator único 
Tabela 12 - Valores de $p$ e $F$ na Anova realizada entre os tutores dos oito polos de pós-graduação

\begin{tabular}{lcccccc}
\hline Fonte da variação & $S Q$ & GI & $M Q$ & $F$ & valor-P & F crítico \\
\hline Entre grupos & 5,46772071 & 7 & 0,7811 & 3,5199 & 0,0046237 & 2,237 \\
\hline Dentro dos grupos & 9,32025449 & 42 & 0,22191 & -- & -- & -- \\
\hline Total & 14,7879752 & 49 & -- & -- & -- & -- \\
\hline
\end{tabular}

ANOVA

Fonte: Os autores.

A análise da ANOVA apresentou um $F$ calculado $(=3,5199)$ superior ao $F$ crítico $(=2,237)$, confirmado pelo $p$ calculado $(=0,0046)$ que é menor que o valor crítico $(=0,05)$, portanto existem diferenças significativas entre as médias de satisfação dos tutores dos oito polos analisados. Também foi feita a verificação, através do teste $t$, para duas amostras, em quais polos as diferenças existiam.

A tabela 13, na próxima página, evidencia que os polos de Nova Tebas, Apucarana, Bituruna e Laranjeiras do Sul diferenciam-se dos demais, ou seja, nesses polos existem diferenças significativas de satisfação em relação aos outros polos.

\section{CONSIDERAÇÕES FINAIS}

Ainda que muitas pessoas acreditem que a educação a distância (EaD) seja uma modalidade de ensino de baixa qualidade, tal conceito está mudando, visto que os cursos oferecidos pela $\mathrm{EaD}$ estão sendo vistos como um meio de retornarem aos estudos, já que estes permitem o acesso por pessoas que possuem tempo limitado, visto que a $\mathrm{EaD}$ possibilita o estudo em casa, com a utilização da internet, por exemplo.

Com base na análise das informações, percebeu-se que tanto tutores, quanto acadêmicos estão satisfeitos com a forma como os cursos do PNAP da Unicentro estão sendo oferecidos, tanto com relação aos professores, conteúdos e materiais, quanto com tutores, atendimento administrativo e suporte técnico prestado.

Entre os principais aspectos que obtiveram melhor avaliação entre os acadêmicos estão o atendimento dos tutores, a facilidade de acesso ao ambiente Moodle e domínio do conteúdo e preparo dos professores para ministrarem as disciplinas. 


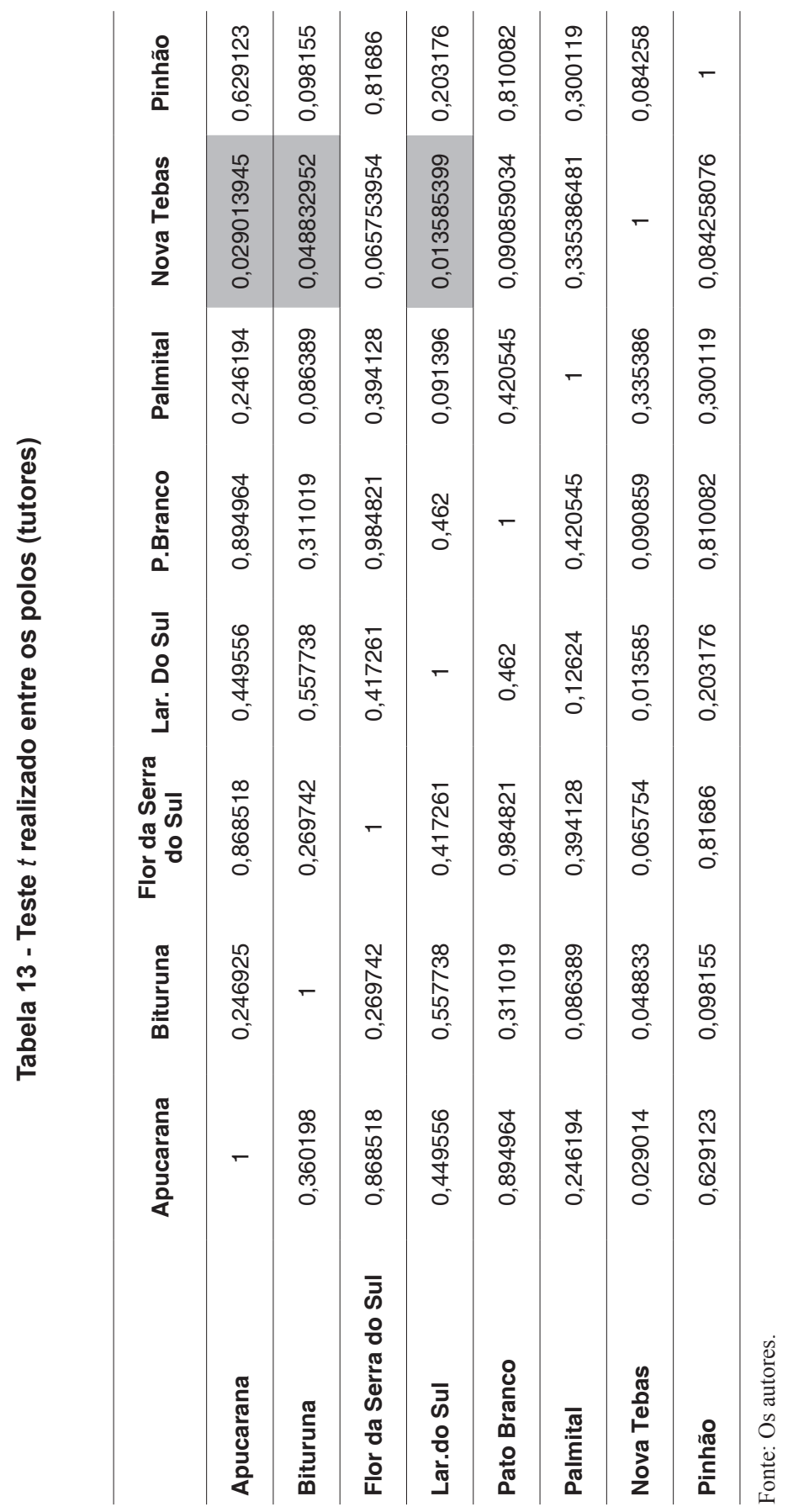


Para os tutores, os aspectos que obtiveram bons índices foram os relacionados com os conteúdos apresentando, onde acreditam que estes estão alinhados com o objetivo dos cursos, o bom relacionamento com os professores, a compatibilidade das avaliações e atividades complementares com o conteúdo apresentado e que os tutores utilizam o ambiente Moodle para compartilhar informações.

Com relação aos pontos a melhorar, o mais citado foi a web conferência, onde tanto acadêmicos quanto tutores acreditam que se essa aula presencial fosse realizada no mesmo dia que a prova da disciplina, haveria um maior número de pessoas participando, visto que atualmente as web conferências acontecem no meio de semana, o que pode dificultar a presença daquelas pessoas que são de fora da cidade, ou que trabalham.

Com base nessa análise pode-se afirmar que o objetivo desse estudo foi atingido, desde que verificou-se que acadêmicos e tutores estão, de modo geral, satisfeitos com o andamento dos cursos do Programa Nacional de Administração Pública oferecido pela Unicentro e que tais cursos estão sendo ofertados com a devida qualidade, mantendo o bom atendimento às solicitações dos acadêmicos, proporcionando professores capacitados e bem preparados, bem como material de apoio adequando ao estudo das pessoas.

Como sugestões para aprimoramento desses cursos, poderiam ser ajustadas as formas de cobrança das web conferências, o qual foi a principal reclamação de acadêmicos e tutores, como apresentação de assuntos mais relevantes e de interesse dos participantes, bem como exposição de aplicações na prática dos conteúdos trabalhados em cada disciplina.

Outro ponto a ser melhorado é relacionado à formação das notas de cada disciplina, onde é solicitado pelos acadêmicos outras formas de avaliação, além da prova. Como por exemplo, a elaboração de atividades em duplas ou grupos, seminários, fóruns, entre outras.

Como limitação desse estudo, pode-se apontar que devido à grande quantidade de acadêmicos e tutores ficou difícil abranger uma amostra maior, já que os cursos a distância contam com aproximadamente 300 acadêmicos em cada polo presencial.

Para possíveis estudos seguintes, poderiam ser realizados com o objetivo de aprofundar a presente pesquisa ou também verificar o grau de satisfação que os acadêmicos do curso de graduação em Administração Pública, bem como com outros acadêmicos, tutores ou professores de cursos a distância de outras áreas. 


\section{REFERÊNCIAS}

AGENCIA DO BRASIL. Matrículas em cursos a distância quase dobram em um ano. Folha de S. Paulo, São Paulo, 27 nov. 2009. Disponível em: <http:// www1.folha.uol.com.br/folha/educacao/ult305u658438.shtml $>$. Acesso em: 25 jun. 2011.

CAPES. Programa Nacional de Formação em Administração Pública PNAP. 2011. Disponível em: <http://www.capes.gov.br/educacao-a-distancia/ pnap>. Acesso em: 05 mar. 2011.

CARVALHO NETO, S. Dimensões da qualidade em ambientes virtuais de aprendizagem. Dissertação (Doutorado) - Faculdade de Economia, Administração e Contabilidade, Programa de Pós-Graduação em Administração da Universidade de são Paulo, São Paulo, 2009.

FORTES, A. V. et al. A satisfação do discente em instituições de ensino superior: um estudo de caso. 2007. In: SIMPÓSIO DE GESTÃO E ESTRATÉGIA EM NEGÓCIOS SEROPÉDICA, 5.,2007, Rio de Janeiro. [ANAIS...], Rio de Janeiro, 2007.

KOTLER, P. Administração de marketing. São Paulo: Pearson/Prentice Hall, 2000.

LENZI, Greicy Kelli Spanhol. Diretrizes para a gestão de projetos de cursos de capacitação na modalidade de educação a distância. 147 p. Dissertação (Mestrado) - Centro Tecnológico, Programa de Pós-Graduação em Engenharia e Gestão do Conhecimento da Universidade Federal de Santa Catarina, Florianópolis, 2010.

MARQUES, J. M. Testes estatísticos: para cursos das áreas biológica e da saúde com uso do computador. Curitiba: Domínio do Saber, 2004.

MAIA, M.C. O uso da tecnologia de informação para a educação a distância no ensino superior. 294 p. Dissertação (Doutorado) -, Escola de Administração de Empresas de São Paulo, Programa de Pós-Graduação em Produção e Sistemas de Informação da Fundação Getulio Vargas, São Paulo, 2003.

MAIA, M. C.; MEIRELLES, F. S. Evasão nos cursos a distância e sua relação com as tecnologias de informação e comunicação. In: ENCONTRO 
DAASSOCIAÇÃO DE PÓS GRADUAÇÃO E PESQUISA EM ADMINISTRAÇÃO (EnANAPD), 29., 2005, Brasília. [ANAIS...], Brasília, 2005.

MELO, P. A.; MELO, M. B.; NUNES, R. S. A educação a distância como política de expansão e interiorização da educação superior no Brasil. Revista de Ciências da Administração, Santa Catarina, v. 11, n. 24, p. 278-304, maio/ ago 2009.

MILAN, G. S.; TREZ, G.. Pesquisa de satisfação: um modelo para planos de saúde. RAE electronica, São Paulo, v. 4, n. 2, dez. 2005 . Disponível em: $<$ http://www.scielo.br/scielo.php?script=sci_arttext\&pid=S167656482005000200002\&lng=pt\&nrm=iso $>$. Acesso em: 5 mar. 2011.

MOORE, M. G.; KEARSLEY, G. Educação a distância: uma visão integrada. São Paulo: Thomson Learning, 2007.

MORAN, J. M. Os modelos educacionais na aprendizagem on-line. 2007. Disponível em: <http://www.eca.usp.br/prof/moran/modelos.htm>. Acesso em: 25 jun. 2011.

NEVES, A. B.; RAMOS, C. F. A imagem das instituições de ensino superior e a qualidade do ensino de graduação: a percepção dos acadêmicos do curso de administração. 2008. Disponível em: <http://www.angrad.org.br/ area_cientifica/artigos/a_imagem_das_instituicoes_de_ensino_superior_e_a qualidade_do_ensino_de_graduacao_a a percepcao_dos_academicos_do_ curso_de_administracao/690/>. Acesso em: 1 jul. 2011.

OLIVEIRA, J. P. L. Ambientes virtuais de aprendizagem e mapas concentuais: um estudo exploratório com alunos do curso de administração de empresas da FEA-RP / USP. Dissertação (Mestrado) - Programa de PósGraduação em Administração da Universidade de São Paulo, São Paulo, 2006.

OLIVEIRA, E. L.; DOMINGUES, M. J. C. S. Tecnologias Educacionais no Ensino a Distância (EaD): Análise das Ferramentas do Ambiente Virtual de Aprendizagem (AVA). In: SEMINÁRIOS EM ADMINISTRAÇÃO (SEMEAD), 11., 2008, São Paulo. [ANAIS...], São Paulo: FEA/USP, 2008.

ONUSIC, L. M. A qualidade de serviços de ensino superior: o caso de uma instituição de ensino público. 154 p. Dissertação (Doutorado) - Faculdade de Economia, Administração e Contabilidade, Programa de Pós-Graduação em Administração da Universidade de São Paulo, São Paulo, 2009. 
OZKUL, F. U.; RENA, B. E. Impact of the e-education on the equal opportunities in education and research on e-accounting course. 2010. Journal of American Academy of Business, Cambridge (Hollywood), v. 16, n. 2, p. 209, mar. 2011.

RODRIGUES, W. C. Metodologia científica. 2007. Disponível em: $<$ http://www4.fct.unesp.br/docentes/educ/alberto/page_download/ METODOLOGIA/metodologia_cientifica.pdf $>$. Acesso em: 25 mar 2011.

RODRIGUES, R. S.; BARCIA, R. M. Modelo de avaliação para cursos no ensino a distância: estrutura, aplicação e avaliação. 125 p. Dissertação (Mestrado) - Programa de Pós-Graduação em Engenharia de Produção da Universidade Federal de Santa Catarina, Florianópolis, 1998.

ROESCH, Sylvia Maria Azevedo. Projetos de estágio e de pesquisa de administração: guia para estágio, trabalhos de conclusão, dissertação e de estudo de caso. 3 ed. São Paulo: Atlas, 2007.

SILVA, V. E. V.; BARROS, J. H. C. O ambiente virtual de aprendizagem "Estácio Campus Virtual" do curso de graduação em administração da UNESA. In: SEMINÁRIOS EM ADMINISTRAÇÃO (SEMEAD), 11., 2008, São Paulo. [ANAIS...], São Paulo: FEA/USP, 2008.

SOUZA, S. A.; REINERT, J. N. Avaliação de um curso de ensino superior através da satisfação/insatisfação discente. Avaliação, Campinas; Sorocaba, v.15, n.1, p. 159-176, 2010.

TAKAHASHI, F. Papel ainda domina o ensino a distância. Folha de S. Paulo, São Paulo, 9 abr. 2006. Disponível em: $<$ http://www1.folha.uol.com. br/folha/educacao/ult305u18541.shtml>. Acesso em: 05 mar. 2011.

UAB. Histórico. 2011. Disponível em: <http://www.uab.capes.gov. br/index.php?option $=$ com_content $\&$ view $=$ article\&id $=9$ :historico$\&$ catid $=6$ :sobre $\&$ Itemid=21>. Acesso em: 5 mar. 2011.

UAB/UNICENTRO. UAB/Unicentro. 2011. Disponível em: <http://web03. unicentro.br/uab/>. Acesso em: 5 mar. 2011.

WATERS, V. A. Satisfaction of students services at tomball college. 2007. 232p. Tese (Doutorado em Filosofia) - University of Texas, Austin, 2007. 